\title{
THE ROLE OF CONDUCTIVE DOPANTS IN POLYMER CHOLESTERIC LIQUID CRYSTALS
}

\author{
Anka Trajkovska Petkoska \\ University St. Kliment Ohridski-Bitola, \\ Faculty of Technology and Technical Sciences, Veles, Republic of Macedonia \\ anka.trajkovska@uklo.edu.mk
}

\begin{abstract}
A variety of conductive dopants were used to modify the electric properties of polymer cholesteric liquid crystals. Different types of carbon blacks and carbon nanotubes, as well as metallic particles were used as conductive dopants in this work. All affected the conductivity of the polymer matrix, but at different dopant concentrations. The percolation threshold behavior of used dopants in the polymer host showed pronounced dependence on the dopants' particle size and particle shape anisotropy. For instance, the higher the aspect ratio of carbon-based dopant particles (aspect ratio = length : diametar), the lower the percolation threshold. Additionally, increase in metallic dopants' diameter yielded higher percolation threshold of polymer composition.
\end{abstract}

Keywords: polymer cholesteric liquid crystals; conductive dopants; carbon black; carbon nanotubes; percolation threshold

\section{УЛОГА НА СПРОВОДЛИВИ ДОПАНТИ ВО ПОЛИМЕРНИ ХОЛИСТЕРИЧНИ ТЕЧНИ КРИСТАЛИ}

Најразлични спроводливи допанти се користени за модификација на својствата на полимерни холистерични течни кристали. Во овој труд како спроводливи допанти се користени различни видови јаглерод и јаглеродни наноцевки, како и метални честички. Сите тие имаат влијание врз полимерната матрица, но при различни концентрации на допантот. Прагот на перколација на користените допанти во полимерната матрица покажа зависност од големината на честиците на допантот и од анизотропијата на обликот на честиците. На пример, поголем сооднос на должината : диаметарот на допантот го намалува прагот на перколација. Понатаму, зголемувањето на дијаметарот на металните честички води кон повисок праг на перколација во полимерната композиција.

Клучни зборови: полимерни холистерични течни кристали; спроводливи допанти; јаглерод; јаглеродни наноцевки; праг на перколација

\section{INTRODUCTION}

Dopants (inclusions or fillers) in polymers have been studied by many researchers for different purposes. There are many particulate substances like carbon-based, metallic, dielectric or inorganic particles, which have been used as dopants in polymers and formed composites with modified and/or unique properties. Particle dopants can be of any shape, e.g. spherical or nonspherical: fiber-like, tubes, flake-platelets; organic or inorganic dopants; conductive or non-conductive dopants. They can be of any size, from nanometer to micron-sizes. The polymeric composites and mixtures comprising dopants can exhibit a variety of modified or improved performances over those of the pure polymer hosts in terms of physical [1, 2], mechanical [3-5], electrical [6-8], 
and thermal properties [9-12] tailoring them to different applications [13-22].

In this work, conductive dopants added to polymer cholesteric liquid crystal host were investigated. It is known that conductive dopants can convert an insulating polymer to electrically conductive polymer mixtures [23-26]. The insulatingto-conducting transition [24] of the polymer composition occurs when the dopant concentration exceeds a critical value known as the percolation threshold (PT) [24, 25, 27-29]. PT is characterized by a sharp jump in the conductivity by several orders of magnitude. The location of the PT depends on many factors, viz. the nature of polymer host, the dopant nature and its size, shape, geometry, and surface energy, the composite porosity, dopant dispersion and alignment, potential chemical interactions, processing method, etc. Generally, it is desirable to have lower PT values, and these can be achieved more easily with elongated dopants [28$30]$ if compared with spherical ones [24, 25, 27]. The aspect ratio of dopants also affects the PT; the higher the dopant aspect ratio, the lower the PT [26, 29]. In addition, better dopant dispersion contributes to lowering PT [31, 32]. However, good alignment, e.g. aligned nanotubes in polymer matrix, does not always give a lower PT [33], because there are only fewer contacts between the aligned nanotubes, resulting in reduction of electrical conductivity, and, consequently, higher PT [26]. Higher PT is expected also in composites where stronger dopant/polymer interactions occur due to the slower creation of conductive network [25, 27]. An increase in the surface tension of the polymer can increase the PT, because it prevents the formation of conductive particle clusters [34].

There are different percolation models which interpret the behavior of the electrical conductivity of different mixtures: statistical, geometrical, thermodynamic and structure-oriented [24, $25,28,35]$. As a classical statistical model explanation of the conductivity of a composite (mixture), $\sigma_{m}$, is due to the existence of "infinite clusters" of connected conducting particles, i.e. formation of a three-dimensional conductive network and is described by a power-law dependence [7, 23, 29, 31, 32, 36-43].

The statistical theory gives a good description of PT. The critical volume fraction for percolation is calculated to be from 5 to $20 \mathrm{vol} \%$ (or even to 50 vol. $\%$ ). However, some disadvantages of this theory have been observed. First of all, it does not take into account the properties of the polymer host (viscosity, surface tension) - polymer/dopant chemical interactions and dopant geo- metry. Second, physical or "electrical" contacts between spherical particles are very important in a description of classical percolation theory. "Continuous chains" of particles do not always exist in conductive composites as the theory assumes [44, 45]. Discontinuities (e.g., thin polymer barrier layers) may occur between the particles [38, 45-47]. In this case, the composites can exhibit a semiconducting or conducting character with conduction occurring through a "tunneling" effect and/or a "hopping" of charge-carriers among neighboring particles. Consequently, much lower percolation thresholds are observed (even lower than 0.1 vol.\%) than the classical theory would predict [31].

Carbon black (CB) has been widely used as conductive dopant to polymers. It consists of spherical shaped, nanosized particles, which usually aggregate in agglomerates with low or high structures. More spherical-like and compact aggregates (or isolated CB particle) have "lower" structure with less pores, voids (less absorption of DBP oil) vs. "high" structure that are elongated, branched and chained aggregates which are more porous and have large effective volume, and, consequently, high DBP value. A large body of published work has been devoted to different polymer/carbon black composites [1, 34, 40, 48-52]. Different loading levels of $\mathrm{CB}$ in polymers have been reported to exhibit percolation thresholds from < 1 vol. $\%$ to tens of vol.\% loads [30]. As stated above, PT strongly depends on the nature of the polymer matrix (e.g., the higher the polymer polarity or surface energy, the higher the PT [34]), CB type (particle size, surface area, oxidation state $[49,51])$, CB structure (the "lower" the structure, the higher the PT $[30,45])$, the adhesion between $\mathrm{CB}$ and polymer [53], the method of the preparation of the composite [48], mixing, and potential addition of salts (which lowers the potential barriers between CB particles) [36, 44, 47]. Depending on the surface treatment of CB particles, different functional and volatile groups (phenols, carboxylic acids) $[49,51,54]$ can exist on the CB surface. A mixing process can even induce an electrical charge on CB particle surface. In most of the cases, $\mathrm{CB}$ particles in polymer composites can have a permanent negative charge on their surfaces $[36,53]$.

On the other hand, carbon nanotubes (CNT), since their discovery [55], have attracted the attention of many researchers for use as dopants, because of their unique properties $[26,56$, 57]. There are different ways for producing CNTs including the arc discharge method, chemical vapor deposition, and laser ablation [58]. They are 
used to make "exceptional" polymer composites [59] with high strength-to-weight ratios [56], and with improved mechanical, thermal, transport, and electrical properties $[1,8,26,52,56]$. CNTs are used in transistor applications as capacitors, actuators, thin, transparent, and flexible conductive films [60-62]. Carbon nanotubes can be single walled carbon nanotubes (SWNT) - a single graphite sheet rolled into a cylinder or tube, double walled carbon nanotubes (DWNT) - two concentric graphene cylinders, or multi-walled carbon nanotubes (MWNT) - coaxially arranged graphene cylinders around a central hollow core [26]. Usually, CNTs are difficult to disperse in a polymer matrix, due to the strong intrinsic Van der Waals attractive forces among CNT particles in combination with a high aspect ratio/high surface area, which causes them to form bundles or ropes [26, 37]. There are ways to overcome this problem using sonication [37, 63], chemical modification of the CNT surface through their purification, and functionalization [64] of nanotubes walls (e.g. oxidization involving carboxylic, carbonyl, and hydroxyl groups [65]), fluorination, alkylation, use of surfactants [66], and organic solvents, chemical vapor deposition (used to roughen the surface and cause better adhesion with the polymer), microwave irradiation [67], and gamma radiation or plasma treatment, which causes chemical alterations to the CNT walls. Different methods for incorporation of CNTs into polymers have also been reported [56], viz. melt mixing, solution mixing, in situ polymerization, and polymer wrapping [26], which can result in lower or higher PT of the $\mathrm{CNT} /$ polymer composite. PT can vary with the use of different types of CNT, or with different polymers [59, 68], depending on the particle-particle interaction as well as interactions with the polymer [31], preparation methods [32] or the use of dispersants, which usually lowers the PT [66]. PT values for CNT in polymers are usually low, i.e. less than 1 wt. $\%$ [1, 23, 31, 37, 39, 40, 56]. Low PTs are beneficial since small dopant concentrations are used to affect the electrical properties, while the other polymer properties remain unaffected. This is very important for the polymer host used in this work, polymer cholesteric liquid crystal (PCLC) host, since its optical (and other) properties will be unaffected after the doping.

Metal-based dopants in polymers have also shown a percolation threshold-type behavior, but this occurs at relatively high dopant loadings. There are many reports on metals used as dopants in a variety of polymers [7, 25, 27, 69-72].
In this work, conductive dopants like carbon-based and metallic dopants in PCLC host have been investigated [41]. The purpose of the study was to improve the dielectric properties of PCLC material [73-77]. By doping with conductive dopants, it was shown "easy" tuning of the electrical properties of PCLC materials and PCLC particles for their potential electro-optical applications, such as: switchable and tunable color filters, tunable optical retarders, polarizers, vehicle camouflage, patterned particles for storage of encoded and encrypted information for the security or military sector; switchable 'paints' and coatings, 'smart windows' for energy or privacy control and many other electro-optical and photonics applications. In information technology, PCLC materials can be used as reflective multi-color information displays, flexible media for information display on either flat or curved surfaces. The concept of electronic paper and sensors based on doped and/or undoped PCLC microparticles is also very attractive for consumers nowadays. PCLC technology platform offers the possibility for a thin, reflective, lightweight, flexible full-color displays that require low energy consumption [41-43, 73-78].

\section{EXPERIMENTAL}

\subsection{Materials}

The polymer cholesteric liquid crystal (PCLC) material used as a polymer matrix in this work is a non-crosslinkable cyclic polysiloxane material. It is left-handed cholesteric liquid crystal that belongs to the class of side-chain liquid crystalline polymers (product of Wacker-Chemie $\mathrm{GmbH}$, Munich, Germany) with a glass transition temperature $\sim 50{ }^{\circ} \mathrm{C}$ and a clearing point $\left(T_{c}\right)$ of $\sim 200{ }^{\circ} \mathrm{C}$ (as measured by the manufacturer [79] and by Korenic [80]). PCLC exhibits unique optical properties, such as selective reflection and circular polarization due to its helical structure, and has the potential in many optical, photonic, and electronic applications (Fig. 1) [41, 75-77].

Dopants used in this work for PCLC are listed in Table 1. Namely, two types of carbon blacks (CB) have been considered: Vulcan PA90 (VPA) and Monarch M120 (M) (products of Cabot Corporation Billerica, MA). CB Vulcan PA90 has particles with a primary diameter of $17 \mathrm{~nm}$, surface area $\sim 140 \mathrm{~m}^{2} / \mathrm{g}$, and DBP oil absorption $\sim 115$ cc/100 g. CB Monarch 120 has particles with a diameter of $\sim 75 \mathrm{~nm}$, surface area $\sim 26.4 \mathrm{~m}^{2} / \mathrm{g}$, and DBP oil absorption $69.2 \mathrm{cc} / 100 \mathrm{~g}$. 


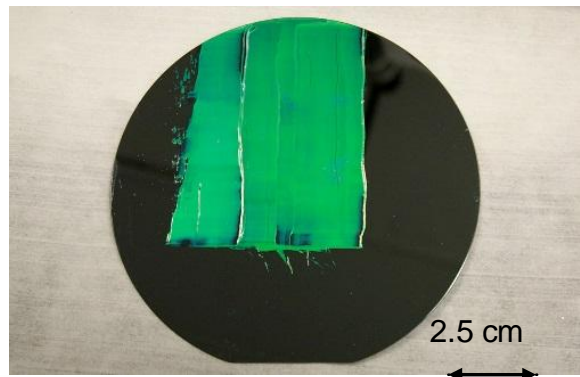

a)

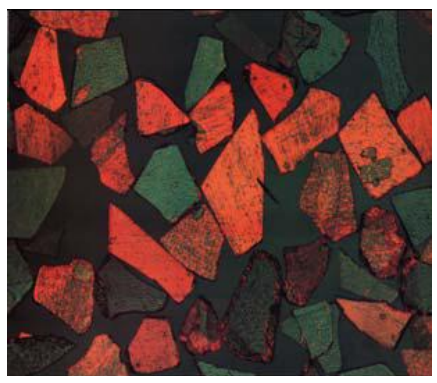

b)

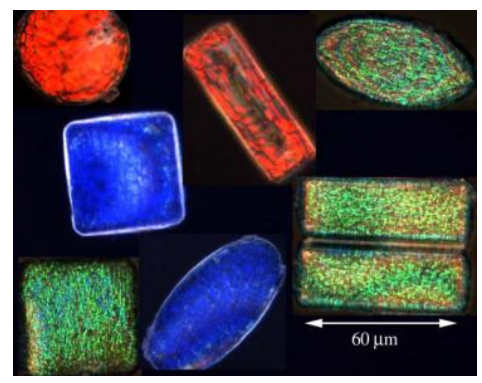

c)

Fig. 1. a) Thin PCLC film prepared on a silicon wafer substrate, b) irregularly shaped PCLC microparticles prepared by freeze-fracturing of the film with liquid nitrogen, c) a composite photo showing red, green, and blue PCLC microparticles in various tailored shapes prepared by soft-lithography technique [41]

CB VPA has a smaller particle size with a high surface area, high structure (forms elongated, branched, and chained aggregates and high DBP value) compared with $\mathrm{CB} \mathrm{M}$. Knowing the properties of these $\mathrm{CB}$ powders, it is expected that $\mathrm{CB}$ VPA will give a higher conductivity as a dopant in PCLC at a lower dopant concentration (low PT value) compared with other types of $\mathrm{CB}$ used in this work.

\section{Table 1}

Dopants for PCLC used in this work

\begin{tabular}{ll}
\hline \hline Dopant & Particle size $^{\text {a) }}$ \\
\hline$\frac{\text { Neat PCLC }}{\text { (no dopant) }}$ & - \\
$\frac{\text { Carbon-based }}{\text { CB VPA }}$ & $17 \mathrm{~nm}$ \\
CB M & $75 \mathrm{~nm}$ \\
SWNT-1 & $1.4 \times 2$ to $5 \mu \mathrm{m}$ \\
SWNT-2 & $1.1 \mathrm{~nm} \times 0.5$ to $100 \mu \mathrm{m}$ \\
MWNT & 10 to $20 \mathrm{~nm} \times 0.5$ to $200 \mu \mathrm{m}$ \\
Metal-based & \\
CI-HQ & $1.1 \mu \mathrm{m}$ \\
ITO & $3.38 \mu \mathrm{m}$ \\
Al flakes & $12 \mu \mathrm{m}$ \\
\hline \hline
\end{tabular}

${ }^{\text {a) }}$ Primary average particle dimensions

Single-walled carbon nanotubes (SWNT-1) are nanotubes of diameters of $1.4 \mathrm{~nm}$ and lengths of 2 to $5 \mu \mathrm{m}$ (product of CarboLex Inc., Lexington, KY). Single-walled carbon nanotubes (SWNT-2) are with diameter of $1.1 \mathrm{~nm}$, and length of 0.5 to $100 \mu \mathrm{m}$ (product of Sigma Aldrich). Multi-walled carbon nanotubes (MWNT's) are with outer diameter of 10 to $20 \mathrm{~nm}$, inner diameter of 5 to 10 $\mathrm{nm}$, and length of 0.5 to $200 \mu \mathrm{m}$ (product of Sigma Aldrich). SWNT-2 particles have a higher aspect ratio than SWNT-1 particles (Table 1), and they are expected to show a lower PT.
Metal-based dopants with different particle sizes have been selected in this study, as well. The metal dopants considered are carbonyl iron (CI), indium tin oxide (ITO), and aluminum particles (Al). [For these dopant particles there are no existing tabulated values of their dielectric properties, however, it is known that the conductivities and dielectric constants of bulk metals are very high.]

Carbonyl iron powder HQ (CI-HQ contains $>97.5 \%$ iron, $0.9 \%$ carbon, $0.5 \%$ oxygen, and $0.9 \%$ nitrogen (product of BASF Corp., Mt. Olive, NJ). Particle diameter is $\sim 1.1 \mu \mathrm{m}$ and density is 7.5 $\mathrm{g} / \mathrm{cm}^{3}$. Indium-tin oxide (ITO) is $99.99+\%$ and particle diameter of $3.38 \mu \mathrm{m}$ (Sigma Aldrich, product \#49468-2). Al flakes are a commercial product designated as Starbrite 4102-EAC (Silberline, Tamaqua, PA) and have been supplied in a liquid dispersion, $10 \%$ particle platelet/90\% ethyl acetate.

\subsection{Preparation of samples for conductivity measurements}

Doped and undoped disks (plates) made from PCLC material and certain amount of dopant are made in order to determine the dielectric properties of the composition. A "thin film-maker tool" with controlled heating and pressure is used for this purpose [41, 43]. Constant-thickness filmmaker for polymers consists of heated platens with temperature control and an air E-Z press, 20-ton hydraulic press (product of International Crystal Laboratories, Garfield, NJ). For each system (PCLC/dopant), $\sim 10$ or more samples with different concentrations are prepared to be $\sim 2 \mathrm{~cm}$ in diameter and $\sim 0.5 \mathrm{~mm}$ in thickness. First, target compositions with specified amounts of PCLCs and dopant material are measured (minimum required solid sample material is $\sim 0.2-0.3 \mathrm{~g}$ or less, depending on the sample thickness), ground by mortar and pestle, and mixed well in a small vibrational capsule. The mixed powders are melted to $130^{\circ} \mathrm{C}$ 
under a load of $\sim 4000 \mathrm{~kg}$, pressed for $\sim 5 \mathrm{~min}$ and then cooled down to a room temperature. Next, prepared disks are measured for their conductivity.

\subsection{Conductivity measurements of PCLC / dopant compositions}

An impedance gain phase analyzer (frequency response analyzer, Solartron 1260 by Solartron Analytical) is designed for the rapid, accurate, and non-destructive measurement of electrochemical phenomena in materials using a special holder for solids. When a voltage (potential) is applied to the material, a current flows through the test chamber that is determined by the mechanisms characterizing the motion of charge within the material [81]. This instrument was used to measure the conductivity for solid pellets of PCLC with and without dopants.

The sample holder for solids (model 1296 2A, Solartron Analytical) is designed to allow accurate impedance tests of solids at room temperature. It consists of two parallel electrodes that form a parallel capacitor. The bottom electrode is fixed in position, and the top electrode can be lowered into contact with the sample. After contact with the sample is made, a measurement of the sample thickness can be taken by reading the dial of a micrometer thickness gauge attached to the top electrode. The sample holders are $20 \mathrm{~mm}$ in diameter and the range of sample thicknesses that can be measured with this technique is from $0.2 \mathrm{~mm}$ to $25.4 \mathrm{~mm}$. The range of measured impedance values varies from $1 \Omega$ to $100 \mathrm{~T} \Omega$ and the frequency region for measurement is from $10 \mu \mathrm{Hz}$ to $32 \mathrm{MHz}$ [82].

Frequency response analysis (FRA) [83] with a sinusoidal test signal was the methodology used to analyze the output impedance signal after interaction with the sample. All calculations are done automatically and the output signal is presented in terms of capacitance, $C$, and resistance, $R$, of the sample as a function of the frequency. Namely, calculations of the dielectric properties of the measured samples placed in the parallel plate capacitor, a circuit where $C$ is in a parallel configuration with $R$ is assumed [41, 84, 85].

SEM micrographs were taken using either an FE SEM LEO 982 (EMSL, Richland, WA) or SEM LEO-EVO 50 [41].

\section{RESULTS AND DISCUSSION}

\subsection{Percolation threshold (PT) of conductive dopants in PCLC host}

All dopants in PCLC host used in this work showed increased conductivity of doped polymer compositions by several orders of magnitude compared with initial neat PCLC when the PT is reached. Different percolation thresholds are observed in this study depending on the dopant type. This polymer host has not been investigated for its dielectric properties previously [41-43, 73, 77].

Percolation threshold for all used dopants in different concentration in PCLC host was determined by measuring conductivity, $\sigma_{\mathrm{m}}$, as a function of doping level for a series of PCLC doped disks. [The calculation is carried out in an iterative manner by first examining the behavior of $\sigma_{\mathrm{m}}$ as a function of doping loading.] Conductivity at $1 \mathrm{kHz}$, which is the same or close to DC conductivity, is reported for all used dopants in Table 2 [36, 41, 43, 47].

T a b le 2

Percolation threshold and conductivity at PT for PCLC/dopant compositions

\begin{tabular}{|c|c|c|}
\hline Dopant & $\begin{array}{l}\text { Concentration } \\
\text { to reach the } \\
\text { percolation } \\
\text { threshold, PT } \\
(\text { vol. } \%)\end{array}$ & $\begin{array}{l}\text { Conductivity } \\
\text { (at } 1 \mathrm{kHz}) \\
\text { at PT }[\mathrm{S} / \mathrm{m}]\end{array}$ \\
\hline$\frac{\text { Neat PCLC }}{\text { (no dopant) }}$ & & $\sim 1 \times 10^{-9}$ \\
\hline \multicolumn{3}{|l|}{ Carbon-based } \\
\hline CB VPA & 2 & $1 \times 10^{-5}$ \\
\hline CB M & 6 & $1 \times 10^{-5}$ \\
\hline SWNT-1 & 0.7 & $1 \times 10^{-6}$ \\
\hline SWNT-2 & 0.4 & $1 \times 10^{-6}$ \\
\hline MWNT & 0.8 & $\sim 1 \times 10^{-3}$ \\
\hline \multicolumn{3}{|l|}{ Metal-based } \\
\hline CI-HQ & 20 & 1 \\
\hline ITO & 25 & $\sim 1 \times 10^{-4}$ \\
\hline Al flakes & 30 & $\sim 1 \times 10^{-2}$ \\
\hline
\end{tabular}

\subsection{SEM imaging of the microstructure of doped PCLC compositions and its correlation with PT}

Figure 2a shows SEM pictures of 5 vol.\% CB VPA doped PCLC material. It can be seen that CB aggregates with sizes $\sim 200-300 \mathrm{~nm}$ are present. The image on the left side (in Fig. 2a) presents a cross section of PCLC film doped with CB VPA, while the other two images are magnified sections where CB VPA aggregates are noticeable. Figure $2 \mathrm{~b}$ compares conductivity at $1 \mathrm{kHz}$ for both CBs / PCLC composites at different dopant loadings. CB VPA dopant shows a jump in mixture conductivity at $\sim 2.0$ vol. $\%$ dopant concentration (it is PT for CB VPA), while CB M shows PT at $\sim 6$ vol.\%. Since CB $M$ is more spherical, it forms more compact aggregates with less pores in the 
polymer matrix (low structure). This is the reason why $\mathrm{CBM}$ has a higher PT than PT value of $\mathrm{CB}$ VPA as a dopant to PCLC host. The reasons for the differences in PT for these CBs in this particular polymer matrix can be summarized as follows: a) different structure of $\mathrm{CBs}$, b) different particle sizes, and c) different surface areas. Also, another contributing factor could be the oxidation state for each CB (not given by the manufacturer), wherein active functional groups on the particle surface contribute to improve or degrade wetting, adsorbing or possible interactions with PCLC.
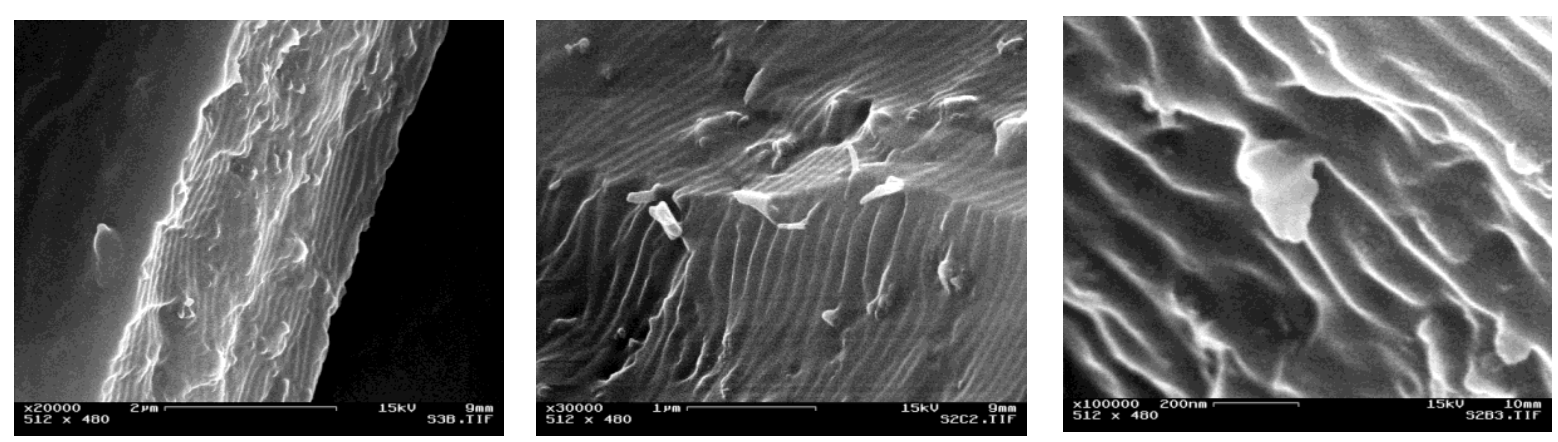

a)

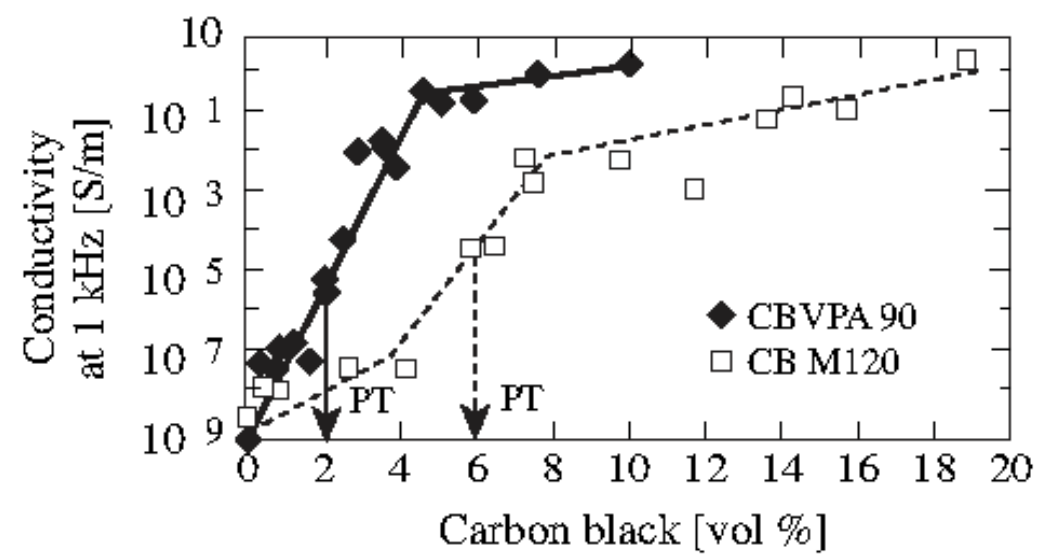

b)

Fig. 2. a) SEM images of 5 vol.\% CB VPA as a dopant in PCLC, b) conductivity of PCLC/CB composites vs. dopant concentration [Lines are drawn to guide the eye.]

Figure 3a are SEM images of SWNT-1 doped PCLC (the image on the left side is top view on PCLC/dopant composite film, while the other two images are cross-sectional view of the doped films). Figure $3 \mathrm{~b}$ compares increased conductivity at $1 \mathrm{kHz}$ for all CNT dopants and their effect on PCLC properties as a function of dopant concentration.

SWNTs have different PTs, which are 0.70 and 0.37 vol. $\%$ for SWNT-1 and SWNT-2, respectively, and both showed a total increase of conductivity at $1 \mathrm{kHz}$ of $\sim 7$ orders of magnitude. Comparing both SWNTs as dopants used in this work, SWNT-2 particles have a higher aspect ratio than SWNT-1 particles (Table 1), and they are expected to show a lower PT. This is the lowest
PT seen for all dopants studied in the present work, most possibly due to the high aspect ratio of these particles. MWNT gives the PT $=0.8$ vol. $\%$ in PCLC; the overall increase in conductivity is $\sim 9$ orders of magnitude. It is known that MWNT can cause a larger increase in conductivity than SWNT in the same polymer due to the fact that they have higher conductivity than SWNT, and, therefore, the conductivity of MWNT-based composites is higher than the conductivity of SWNTbased composites. On the other hand, SWNT with higher aspect ratio (e.g. longer length of CNT) could achieve "easier" connection and "conductive paths" through the polymeric matrix, and, consequently, have lower PT [32, 41, 43]. 

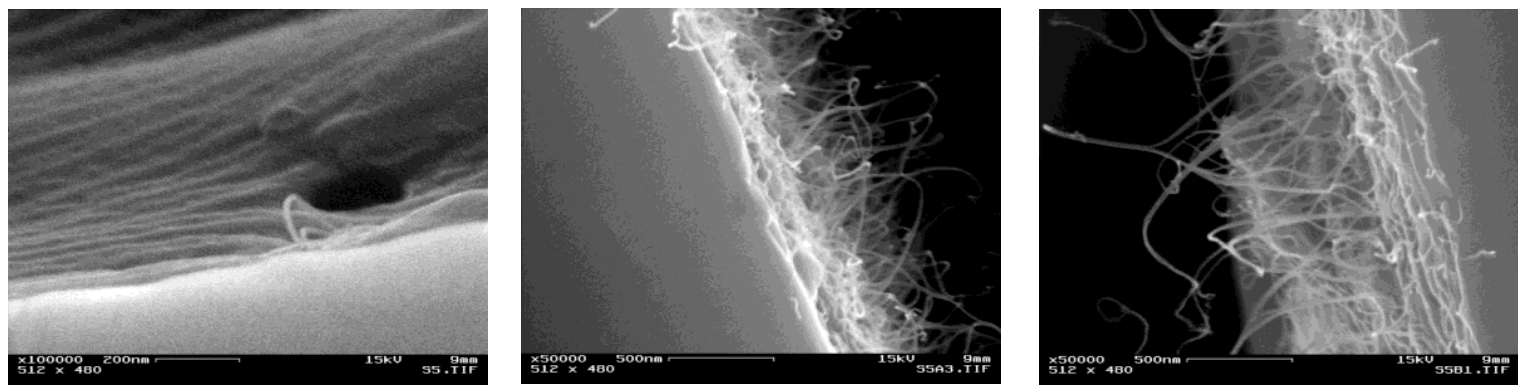

a)

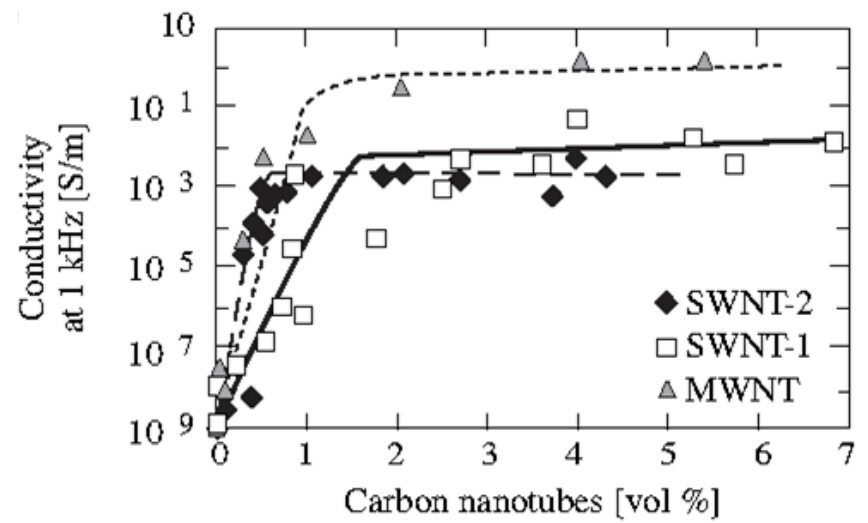

b)

Fig. 3. a) SEM images of 1.2 vol.\% SWNT-1/PCLC composites, b) conductivity of different polymer compositions based on PCLC/CNTs vs. dopant concentration [Lines are drawn to guide the eye.]

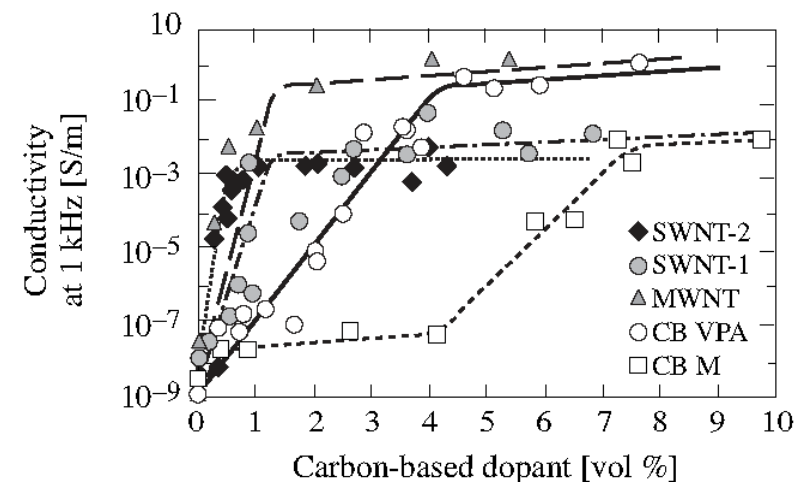

Fig. 4. Carbon-based dopants: comparison of conductivity at $1 \mathrm{kHz}$ vs. dopant concentration for different PCLC/dopant compositions

Conductivity data for all used carbon-based dopants in PCLC host are summarized in Figure 4.

In general, metal-based dopants show high percolation thresholds. CI-HQ increases the conductivity of PCLC/CI-HQ composites by nine orders of magnitude at a dopant level of $20 \mathrm{vol} . \%$ (PT). Similar behavior was observed by Zois et al. [25, 71] for micron-sized Fe-particles in other polymers. ITO as a dopant increases the conductivity of ITO/PCLC composites by eight orders of magnitude at doping levels of $\sim 25$ to $30 \mathrm{vol} \%$, while PT for Al flakes is

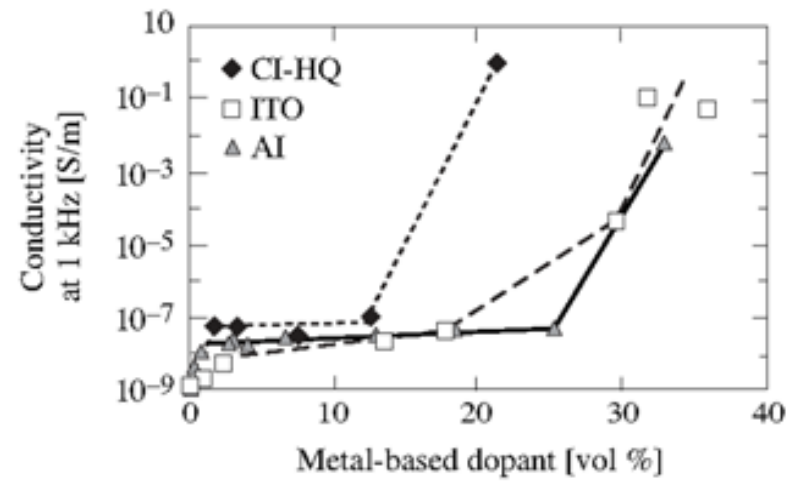

Fig. 5. Metal-based dopants: comparison of conductivity at $1 \mathrm{kHz}$ vs. dopant concentration for different PCLC/dopant compositions

at 30 vol.\% or higher. All metal-based dopants in PCLC host are compared in Figure 5.

Figure 6 summarizes all conductive dopants in PCLC host. There are two types of behavior for dopants in PCLC matrix: a) carbon-based particles in PCLC host show that PT drops as shape anisotropy increases. This behavior has been observed in other polymer hosts, too [59]; b) for metal-based particles with little shape anisotropy in PCLC: PT increases with increasing particle size (CI-HQ, ITO, Al flakes) [41, 43]. 


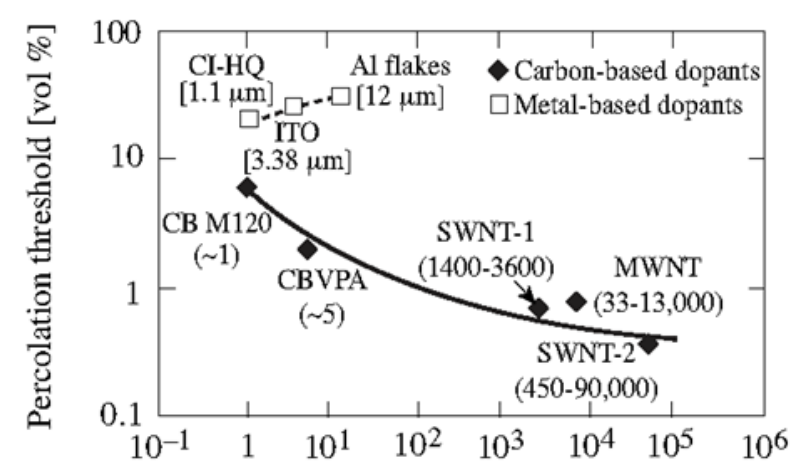

( ) Aspect ratio of dopant or [ ] particle size [ $\mu \mathrm{m}]$

Fig. 6. PT vs. dopant average aspect ratio (range given in parentheses) or particle size [given in brackets]

[Lines are drawn to guide the eye.]

\section{CONCLUSION}

Increased conductivity or enhanced dielectric properties of a variety of polymers have been studied by many authors [24-27, 86-89]. This is of particular interest as regards polymers because their properties can be easily modified by doping. Moreover, the polymeric mixtures can exhibit improvements of their physical, mechanical, electrical, and thermal properties, compared with the properties of the neat polymer host. The properties of the composition can be "tailored" to particular novel applications by selecting a proper type (nature, size, shape) of dopants and its loading in the polymer matrix.

Conductive particles in general show percolation threshold behavior when used as dopants in polymers. In this work, selected types of conductive dopants (carbon- and metal-based dopants) showed the same behavior in PCLC matrix. The increase of the conductivity of doped PCLC material was by several orders of magnitude over that of pure PCLC host, which has not been observed before for this type of polymer host. Particularly, carbon-based dopants increased the conductivity for $\sim 8$ orders of magnitude (for carbon black, CB VPA), while MWNT increased it for $\sim 9$ orders of magnitude. Furthermore, two types of behavior of investigated conductive dopants were observed:

i) For carbon-based dopants, percolation threshold drops as shape anisotropy increases (Fig. 4). This type of behavior has been observed by other scientists for different polymer hosts.

ii) For metal-based dopants with little or no shape anisotropy, the percolation threshold in PCLC material increases with increasing particle size (Fig. 5).

The PCLC material in this study was of particular interest for the author, because it possesses unique optical properties, such as selective reflection and circular polarization of the reflected light due to the helical structure [41]. By its doping, the use of PCLC material extends to novel optical, photonic, and electronic applications. The most important are electro-optical applications, such as display and sensor applications, color filters, "smart" windows, electronic labels, and electromagnetic shielding, besides the known passive applications like use in the military as decals, decorative/cosmetic inks and paints, document security, stereoscopic printing, retarders, waveplates, filters, polarisers, etc. To the best knowledge of the author, this polymer host has not been investigated by other scientists in terms of conductive doping and change of its properties [41, 42, 73, 75, 77].

Acknowledgment. This work was done at the University of Rochester, Laboratory for Laser Energetics in Rochester, NY, USA. The author thanks Prof. Steve D. Jacobs for his guidance and supervision throughout this project, and Mr. Kenneth Marshall and Dr. Tanya Kosc for their constructive advice and help. The author also acknowledges the generous Horton Fellowship support of the Laboratory for Laser Energetics.

\section{REFERENCES}

[1] B. J.-P. Adohi, A. Mdarhri, C. Prunier, B. Haidar, C. Brosseau, A comparison between physical properties of carbon black-polymer and carbon nanotubes - polymer composites, Journal of Applied Physics 108, 074108 (2010).

[2] T. Hanem Ann, K. Honnef, Polymer-dopant-systems: Tailoring of optical and thermomechanical properties, $C P 1255, V$-th International Conference on Times of Polymers (TOP) and Composites, A. D'Amore, D. A. Cierno, L. Grassia (Eds.), American Institute of Physics, 2010.

[3] R. Suihkonen, K. Nevalainen, O. Orell, M. Honkanen, L. Tang, H. Zhang, Z. Zhang, J. Vuorinen, Performance of epoxy filled with nano- and micro-sized magnesium hydroxide, J. Mater. Sci. 47, 1480-1488 (2012).

[4] L. Chen, K. Liu, T. X. Jin, F. Chen, Q. Fu, Rod like attapulgite/poly(ethylene terephtalate) nanocomposites with chemical bonding between the polymer chain and the filler, eEXPRESS Polymer Letters 6(8), 629-638 (2012).

[5] V. V. Zuev, S. V. Kostromin, A. V. Shlykov, The effect of fullerene fillers on the mechanical properties of polymer nanocomposites, Mechanics of Composite Materials 46(2), (2010).

[6] O. Okhay, R. Krishna, M. Salimian, E. Titus, J. Gracio, L. M. Guerra, J. Ventura, Conductivity enhancement and resistance changes in polymer films filled with reduced graphene oxide, Journal of Applied Physics 113, 064307 (2013).

[7] A. Qureshi, A. Gen, M. S. Eroglu, N. L. Singh, A. Gulluoglu, Dielectric properties of polymer composites filled with different metals, Journal of Macromolecular 
Science, Part A: Pure and Applied Chemistry 45, 462 469 (2008).

[8] J. Leng, H. Lv, Y. Liu, S. Du, Electroactivate shapememory polymer filled with nanocarbon particles and short carbon fibers, Applied Physics Letters 91, 144105 (2007).

[9] S. Saengsuwan, S. Saikrasun, Thermal stability of styrene-(ethylene butylene)-styrene-based elastomer composites modified by liquid crystalline polymer, clay, and carbon nanotube, J. Therm. Anal Calorim. 110, 1395140 (2012).

[10] Y. M. Shabana, G.T.Wang, Thermomechanical modeling of polymer nanocomposites by the asymptotic homogenization method, Acta Mech. 224, 1213-1224 (2013).

[11] X. J. Wang, The effect of the prismatic filler arrangement and cross-sectional shape on the thermal conductivity of polymer composites, eEXPRESS Polymer Letters 8(12), 920-931 (2014).

[12] H. T. Oyama, M. Sekikawa, Y. Ikezawa, Influence of the polymer/inorganic filler interface on the mechanical, thermal, and flame retardant properties of polypropylene/magnesium hydroxide composites, Journal of $\mathrm{Ma}$ cromolecular Science, Part B: Physics 50, 463-483 (2011).

[13] M. Madani, Conducting carbon black filled NR/IIR blend vulcanizates: Assessment of the dependence of physical and mechanical properties and electromagnetic interference shielding on variation of filler loading, $J$. Polym. Res. 17, 53-62 (2010).

[14] X. Jin, M. Deng, S. Kaps, X. Zhu, I. Holken, K. Mess, R. Adelung, Y. K. Mishra, Study of tetrapodal ZnOPDMS composites: A comparison of fillers shapes in stiffness and hydrophobicity improvements, PLOS ONE 9 (9), e106991 (2014).

[15] S. M. Zabihzadeh, Water uptake and flexural properties of natural filler/HDPE composites, BioResources 5(1), 316-323 (2010).

[16] A. Ghosh, L. Ma, C. Gao, Zeolite molecular sieve 5A acts as a reinforcing filler, altering the morphological, mechanical, and thermal properties of chitosan, $\mathrm{J} . \mathrm{Ma}$ ter. Sci. 48, 3926-3935 (2013).

[17] A. S. Ermilov, E. M. Nurullaev, Optimization of fractional composition of the filler of elastomer composites, Mechanics of Composite Materials 49(3) (2013).

[18] V. Mittal, Modelling and prediction of barrier properties of polymer layered silicate nanocomposites, Polymers \& Polymer Composites 21(8), 509-517 (2013).

[19] M. Bărbuţă, M. Harja, I. Baran, Comparison of mechanical properties for polymer concrete with different types of filler, Journal of Materials in Civil Engineering, SCE 696 (2010).

[20] L. Lee, I.-J. Kim, S. Yang, S. Kim, Electrochemical properties of PEO/PMMA blend-based polymer electrolytes using imidazolium salt-supported silica as a filler, Res. Chem. Intermed 39, 3279-3290 (2013).

[21] J. A. Covington, J. W. Gardner, Carbon Nanomaterial Polymer Composite ChemFET and Chemoresistors for Vapour Sensing, CP1137, Olfaction and Electronic
Nose: Proceedings of the $13^{\text {th }}$ International Symposium, M. Pardo and G. Sberveglieri (Eds.), 2009.

[22] Aga and $\mathrm{Mu}$, Doping of Polymers with $\mathrm{ZnO}$ Nanostructures for Optoelectronic and Sensor Applications, $\mathrm{Na}$ nowires Science and Technology, Nicoleta Lupu (Ed.), ISBN: 978-953-7619-89-3, InTech, 205-222 (2010).

[23] A. Combessis, L. Bayon, L. Flandin, Effect of filler auto-assembly on percolation transition in carbon nanotube/polymer composites, Applied Physics Letters 102, 011907 (2013)

[24] A. Maaroufi, K. Haboubi, A. El Amarti, F. Carmona, Electrical resistivity of polymeric matrix loaded with nickel and cobalt powders, Journal of Materials Science 39(1), 265-270 (2004).

[25] H. Zois, L. Apekis, Y. P. Mamunya, Structure-electrical properties relationships of polymer composites filled with Fe-powder, Macromolecular Symposia 194, 351359 (2003)

[26] M. Moniruzzaman, K. I. Winey, Polymer nanocomposites containing carbon nanotubes, Macromolecules 39(16), 5194-5205 (2006).

[27] H. Zois, Y. P. Mamunya, L. Apekis, Structure and dielectric properties of a thermoplastic blend containing dispersed metal, Macromolecular Symposia 198, 461472 (2003)

[28] F. Lux, Models proposed to explain the electrical conductivity of mixtures made of conductive and insulating materials, Review. Journal of Materials Science 28, 285-301 (1993).

[29] C. A. Martin, J. K. W. Sandler, M. S. P. Shaffer, M. K. Schwarz, W. Bauhofer, K. Schulte, A. H. Windle, Formation of percolating networks in multi-wall carbonnanotube-epoxy composites, Composites Science and Technology 64(15), 2309-2316 (2004).

[30] I. Balberg, A comprehensive picture of the electrical phenomena in carbon black-polymer composites, $\mathrm{Car}$ bon 40, 139-143 (2001).

[31] J. K. W. Sandler, J. E. Kirk, I. A. Kinloch, M. S. P. Shaffer, A. H. Windle, Ultra-low electrical percolation threshold in carbon-nanotube-epoxy composites, Polymer 44(19), 5893-5899 (2003).

[32] X. Jiang, Y. Bin, M. Matsuo, Electrical and mechanical properties of polyimide-carbon nanotubes composites fabricated by in situ polymerization, Polymer 46, 74187424 (2005).

[33] F. M. Du, J. E. Fischer, K. I. Winey, Effect of nanotube alignment on percolation conductivity in carbon nanotube/polymer composites, Physical Review B 72(12), 121404 (2005)

[34] K. Miyasaka, K. Watanabe, E. Jojima, H. Aida, M. Sumita, K. Ishikawa, Electrical-conductivity of carbon polymer composites as a function of carbon content, Journal of Materials Science 17(6), 1610-1616 (1982).

[35] M. Johlitz, S. Diebels, Effective mechanical behavior of filled polymers, Mechanics of Advanced Materials and Structures 18, 106-114 (2011).

[36] L. Flandin, T. Prasse, R. Schueler, K. Schulte, W. Bauhofer, J. Y. Cavaille, Anomalous percolation transition 
in carbon-black-epoxy composite materials, Physical Review B 59 (22), 14349-14355 (1999).

[37] C. Park, Z. Ounaies, K. A. Watson, R. E. Crooks, J. Smith, S. E. Lowther, J. W. Connell, E. J. Siochi, J. S. Harrison, T. L. S. Clair, Dispersion of single wall carbon nanotubes by in situ polymerization under sonication, Chemical Physics Letters 364(3-4), 303-308 (2002).

[38] Z. Ounaies, C. Park, K. E. Wise, E. J. Siochi, J. S. Harrison, Electrical properties of single wall carbon nanotube reinforced polyimide composites, Composites Science and Technology 63(11), 1637-1646 (2003).

[39] S. Barrau, P. Demont, A. Peigney, C. Laurent, C. Lacabanne, DC and AC conductivity of carbon nanotubespolyepoxy composites, Macromolecules 36(14), 51875194 (2003).

[40] B. E. Kilbride, J. N. Coleman, J. Fraysse, P. Fournet, M. Cadek, A. Drury, S. Hutzler, S. Roth, W. J. Blau, Experimental observation of scaling laws for alternating current and direct current conductivity in polymer-carbon nanotube composite thin films, Journal of Applied Physics 92(7), 4024-4030 (2002).

[41] A. Trajkovska Petkoska, Polymer Cholesteric Liquid Crystal Flakes - Their Electro Optic-Behaviour for Potential E-Paper Application, Verlag Dr. Müller, VDM ISBN 978-3-639-06439-1, Germany, 2008.

[42] A. Trajkovska-Petkoska, S. D. Jacobs, K. L. Marshall, T. Z. Kosc, Electrically Actuated Doped Polymer Flakes and Electrically Addressable Optical Devices Using Suspensions of Doped Polymer Flakes in a Fluid Host, U.S. 7,713,436 B1 (2010).

[43] A. Trajkovska-Petkoska, S. D. Jacobs, Effect of different dopants on polymer cholesteric liquid crystals, Mol. Cryst. Liq. Cryst. 495, 334 (2008).

[44] R. Schueler, J. Petermann, K. Schulte, H. P. Wentzel, Agglomeration and electrical percolation behavior of carbon black dispersed in epoxy resin, Journal of Applied Polymer Science 63(13), 1741-1746 (1997).

[45] I. Balberg, Tunneling and nonuniversal conductivity in composite-materials, Physical Review Letters 59(12), 1305-1308 (1987).

[46] F. Carmona, Conducting filled polymers, Physica $A$ 157(1), 461-469 (1989).

[47] M. T. Connor, S. Roy, T. A. Ezquerra, F. J. B. Calleja, Broadband AC conductivity of conductor-polymer composites, Physical Review B 57(4), 2286-2294 (1998).

[48] Y. Imai, T. Fueki, T. Inoue, A.-A. K. Oto, A new direct preparation of electroconductive polyimide/carbon black composite via polycondensation of nylon-salt type monomer/carbon black mixture, Journal of Polymer Science: Part A: Polymer Chemistry 36, 1031-1034 (1998).

[49] T. Prasse, M. K. Schwarz, K. Schulte, W. Bauhofer, The interaction of epoxy resin and an additional electrolyte with non-oxidised carbon black in colloidal dispersions, Colloids and Surfaces, A: Physicochemical and Engineering Aspects 189(1-3), 183-188 (2001).

[50] H. Zois, L. Apekis, M. Omastova, Electrical properties of carbon black-filled polymer composites, Macromolecular Symposia 170, 249-256 (2001).
[51] Cabot Corporation, The Fundamentals of Carbon Black, Billerica Technical Center, Billerica, MA.

[52] S. Agnelli, V. Cipolletti, S. Musto, M. Coombs, L. Conzatti, S. Pandini, T. Riccò, M. Galimberti, Interactive effects between carbon allotrope fillers on the mechanical reinforcement of polyisoprene based nanocomposites, eEXPRESS Polymer Letters, 8(6), 436-449 (2014).

[53] T. Prasse, L. Flandin, K. Schulte, W. Bauhofer, In situ observation of electric field induced agglomeration of carbon black in epoxy resin, Applied Physics Letters 72(22), 2903-2905 (1998).

[54] J. K. Foster, Effects of carbon black properties on conductive coatings, presented at the 2nd International Exhibition of Paint Industry Suppliers, Sao Paulo, Brasil, 1991.

[55] S. Iijima, Helical microtubules of graphitic carbon, $\mathrm{Na}$ ture 354 (6348), 56-58 (1991).

[56] O. Breuer, U. Sundararaj, Big returns from small fibers: A review of polymer/carbon nanotube composites, $\mathrm{Po}$ lymer Composites 25(6), 630-645 (2004).

[57] M. S. Dresselhaus, G. Dresselhaus, A. Jorio, Unusual properties and structure of carbonnanotubes, Annual Review of Materials Research 34, 247-278 (2004).

[58] T. W. Ebbesen, Carbon nanotubes, Annual Review of Materials Science 24, 235-264 (1994).

[59] P. Collins, J. Hagerstrom, Creating high performance conductive composites with carbon nanotubes, Hyperion Catalysis International.

[60] R. H. Baughman, A. A. Zakhidov, W. A. de Heer, Carbon nanotubes - the route toward applications, Science 297(5582), 787-792 (2002).

[61] L. M. Clayton, A. K. Sikder, A. Kumar, M. Cinke, M. Meyyappan, T. G. Gerasimov, J. P. Harmon, Transparent poly(methyl methacrylate)/single-walled carbon nanotube (PMMA/SWNT) composite films with increased dielectric constants, Advanced Functional Materials 15(1), 101-106 (2005).

[62] K. A. Watson, S. Ghose, D. M. Delozier, J. G. Smith, J. W. Connell, Transparent, flexible, conductive carbon nanotube coatings for electrostatic charge mitigation, Polymer 46(7), 2076-2085 (2005).

[63] K. L. Lu, R. M. Lago, Y. K. Chen, M. L. H. Green, P. J. F. Harris, S. C. Tsang, Mechanical damage of carbon nanotubes by ultrasound, Carbon 34(6), 814-816 (1996).

[64] C. A. Dyke, J. M. Tour, Overcoming the insolubility of carbon nanotubes through high degrees of sidewall functionalization, Chemistry A, European Journal 10(4), 813-817 (2004).

[65] T. W. Ebbesen, H. Hiura, M. E. Bisher, M. M. J. Treacy, J. L. Shreeve Keyer, R. C. Haushalter, Decoration of carbon nanotubes, Advanced Materials 8(2), 155-157 (1996).

[66] S. Barrau, P. Demont, E. Perez, A. Peigney, C. Laurent, C. Lacabanne, Effect of palmitic acid on the electrical conductivity of carbon nanotubes-epoxy resin composites, Macromolecules 36(26), 9678-9680 (2003).

[67] K. Kubota, M. Sano, T. Masuko, Microwave irradiation for chemical modification of carbon nanotubes for better 
dispersion, Japanese Journal of Applied Physics, Part 1: Regular Papers Short Notes \& Review Papers 44(1A), 465-468 (2005).

[68] I. A. Tchmutin, A. T. Ponomarenko, E. P. Krinichnaya, G. I. Kozub, O. N. Efimov, Electrical properties of composites based on conjugated polymers and conductive fillers, Carbon 41(7), 1391-1395 (2003).

[69] M. Mitov, F. de Guerville, C. Bourgerette, Evidence of surface segregation in the organization of metallic nanoparticles dispersed in a cholesteric liquid crystal, Molecular Crystals and Liquid Crystals 435, 673 (2005).

[70] M. Mitov, C. Portet, C. Bourgerette, E. Snoeck, M. Verelst, Long-range structuring of nanoparticles by mimicry of a cholesteric liquid crystal, Nature Materials 1(4), 229-231 (2002).

[71] H. Zois, L. Apekis, Y. P. Mamunya, Dielectric properties and morphology of polymer composites filled with dispersed iron, Journal of Applied Polymer Science 88(13), 3013-3020 (2003).

[72] Y. C. Wang, C. Anderson, Formation of thin transparent conductive composite films from aqueous colloidal dispersions, Macromolecules 32(19), 6172-6179 (1999).

[73] A. Trajkovska-Petkoska, S. D. Jacobs, T. Z. Kosc, K. L. Marshall, Manufacture of Regularly Shaped Polymer Cholesteric Liquid Crystal Flakes with a Mechanically Flexible Mold, U.S. Pat. 7,238,316 B2 (2007).

[74] A. Trajkovska-Petkoska, R. Varshneya, T. Z. Kosc, K. L. Marshall, S. D. Jacobs, Enhanced electro-optic behavior for shaped polymer cholesteric liquid crystal (PCLC) flakes made by soft lithography, Adv. Funct. Mater. 15, 217 (2004).

[75] A. Trajkovska-Petkoska, S. D. Jacobs, The Manufacture, characterization, and manipulation of polymer cholesteric liquid crystal flakes and their possible applications, Journal of Materials Science and Engineering (A\&B), A2 2, 137-151 (2012).

[76] T. Z. Kosc, K. L. Marshall, A. Trajkovska-Petkoska, E. Kimball, S. D. Jacobs, Progress in the development of polymer cholesteric liquid crystal flakes for display applications, Displays, 25, 171-176 (2004).

[77] A. Trajkovska-Petkoska, Polymer cholesteric liquid crystal flakes as new candidates for display and sensor applications, NATO Science for Peace and Security, Se- ries B: Physics and Biophysics: Nanotechnological Basis for Advanced Sensors, Springer, 2011.

[78] A. Trajkovska-Petkoska, T. Z. Kosc, K. L. Marshall, K. Hasman, S. D. Jacobs, Motion of doped polymer cholesteric liquid crystal flakes in a direct-current electric field, J. Appl. Phys, 103, 094907 (2008).

[79] Consortium für Elektrochemische Industrie $\mathrm{GmbH}$, Central Research Company of Wacker Chemie $\mathrm{GmbH}$, Zielstattstr. 20, D-8000 München 70, Germany.

[80] E. M. Korenic, Colorimetry of Cholesteric Liquid Crystals, PhD Thesis, University of Rochester, Rochester, NY, 1997.

[81] N. D. Cogger, N. J. Evans, An introduction to electrochemical impedance measurement, Technical report, No. 6, Solartron Analytical (May, 1999).

[82] Standard test methods for AC loss characteristics and permittivity (dielectric constant) of solid electrical insulation, Designation D 150-95, ASTM Standard.

[83] P. E. Wellstead, Frequency response analysis, Technical report 10, Solartron Analytical, Control System Principles, Cheshire, UK, 2003.

[84] A. S. Riad, M. T. Korayem, T. G. Abdel-Malik, AC conductivity and dielectric measurements of metal-free phthalocyanine thin films dispersed in polycarbonate, Physica, B 270(1-2), 140-147 (1999).

[85] H. Ye, C. Q. Sun, H. Huang, P. Hing, Dielectric behavior of nanostructured diamond films, Applied Physics Letters 78(13), 1826-1828 (2001).

[86] M. Nagaraja, H. M. Mahesh, J. Manjanna, K. Rajanna, M. Z. Kurian, S. V. Lokesh, Effect of multiwall carbon nanotubes on electrical and structural properties of polyaniline, Journal of Electronic Materials, 41(7), (2012).

[87] S. Palaty, K. J. Mary, J. Honey, P. V. Devi, Effect of dopants and preparation conditions on the conductivity of polyaniline, Progress in Rubber, Plastics and Recycling Technology, 26(3) (2010).

[88] Y. Mamunya, Carbon Nanotubes as Conductive Filler in Segregated Polymer Composites - Electrical Properties, Carbon Nanotubes - Polymer Nanocomposites, Dr. Siva Yellampalli (Ed.), (2011) ISBN: 978-953-307-4986, InTech.

[89] J. L. Alan Kin-Tak Lau, Multifunctional Polymer Nanocomposites, Taylor and Francis Group, LLC, 2011. 
